\title{
Crisis, retornos y emprendimientos. El caso de los migrantes ecuatorianos y el Fondo Cucayo
}

Crises, retours et entrepreneuriats. Le cas des migrants équatoriens et le Fonds Cucayo

Crisis, Returns and Entrepreneurship. The Case of Ecuadorian Migrants and the Cucayo Fund

Ronny Correa, Joan Lacomba y Santiago Ochoa

\section{(2) OpenEdition \\ Journals}

\author{
Edición electrónica \\ URL: https://journals.openedition.org/remi/7813 \\ DOI: $10.4000 /$ remi.7813 \\ ISSN: $1777-5418$ \\ Editor \\ Université de Poitiers \\ Edición impresa \\ Fecha de publicación: 1 septiembre 2016 \\ Paginación: 95-120 \\ ISBN: 979-10-90426-27-6 \\ ISSN: 0765-0752 \\ Referencia electrónica \\ Ronny Correa, Joan Lacomba y Santiago Ochoa, «Crisis, retornos y emprendimientos. El caso de los \\ migrantes ecuatorianos y el Fondo Cucayo», Revue européenne des migrations internationales [En línea], \\ vol. 32 - n² | 2016, Publicado el 01 septiembre 2018, consultado el 15 abril 2022. URL: http:// \\ journals.openedition.org/remi/7813; DOI: https://doi.org/10.4000/remi.7813
}




\title{
Crisis, retornos y emprendimientos. El caso de los migrantes ecuatorianos y el Fondo Cucayo
}

\author{
.. Ronny Correa ${ }^{1}$, Joan Lacomba ${ }^{2}$ y \\ Santiago Ochoa ${ }^{3}$
}

\section{Introducción}

Entre finales de 1999 y comienzos del 2000, coincidiendo con la grave crisis vivida en Ecuador y la dolarización de su economía, se inició un flujo de migrantes ecuatorianos prácticamente desconocido hasta el momento. Este movimiento migratorio se dirigió principalmente hacia España y, en menor medida, hacia otros países europeos como Italia. También hacia el norte del continente americano, donde la migración de los ecuatorianos a los Estados Unidos contaba ya con mayor tradición - la Secretaría Nacional del Migrante (SENAMI) calculaba en 2014 que son entre 2 y 3 millones los migrantes ecuatorianos en todo el mundo. La que se conoció como "estampida migratoria» trajo, solo a España, a cerca de 500.000 ecuatorianos en un breve período de cinco años. Sin embargo, tras una decena de años de emigración ininterrumpida hacia Europa y Estados Unidos, a partir de 2010 - cuando los efectos de la crisis económica internacional iniciada en 2008 ya eran claramente visibles - un número considerable de ecuatorianos comenzaron a tomar el camino de vuelta hacia sus lugares de origen. Muchos de ellos habían pasado en el exterior largos períodos de tiempo y dudaban sobre la conveniencia o no de su regreso. Al mismo tiempo, la reducción del número de migrantes ecuatorianos fue acompañada de un descenso en los envíos de remesas hacia el país de origen, con un importante impacto sobre la economía del país que pudo verse amortiguado en parte por el propio crecimiento interno.

1 Docente investigador, director del Departamento de Economía y responsable del Departamento de Desarrollo Económico de la Universidad Técnica Particular de Loja, San Cayetano Alto, Calle París, Loja, Ecuador; rfcorrea@utpl.edu.ec

2 Doctor en Sociología por la Universidad de Valencia y profesorTitular en el Departamento de Trabajo Social. Imparte clases en la Facultad de Ciencias Sociales de la Universidad de Valencia, Departament de Treball Social. Despatx P1-22, Facultat Ciències Socials Universitat de València-Campus Tarongers, Avenida Tarongers 4-B 46021 Valencia; joan.lacomba@uv.es

3 Docente investigador en la Sección Departamental de Métodos Cuantitativos de la Universidad Técnica Particular de Loja, San Cayetano Alto, Calle París, Loja, Ecuador; wsochoa@utpl.edu.ec 
De este modo, mientras que en los países de residencia la situación socioeconómica se deterioró, los indicadores de desarrollo de Ecuador experimentaron ciertas mejoras que pudieron animar a los migrantes a retornar. Si en buena parte de los países de emigración se produjo una dramática caída del crecimiento económico y del empleo, en Ecuador se aceleró el dinamismo económico y se generaron nuevas oportunidades, pese a los retos que enfrenta aún el país. En cualquier caso, la mayor parte de los ecuatorianos residentes en el exterior han seguido viviendo allí, como muestra de las diferencias que todavía siguen existiendo entre los niveles de desarrollo de los países de emigración y Ecuador, pero también debido a los cambios que entraña la migración y a las dificultades que acompañan tanto a la decisión de emigrar como a la de retornar.

El principal objetivo de este artículo es mostrar cómo entre aquellos que retornaron se generaron experiencias dirigidas al autoempleo, aprovechando tanto la positiva coyuntura económica en Ecuador como, sobre todo, las políticas del Estado orientadas al emprendimiento de los que regresaron al país. La puesta en marcha de dispositivos como el Fondo Cucayo ${ }^{4}$ - inserto dentro de un plan gubernamental de medidas más amplio para facilitar el retorno - ha tenido un efecto del que aún es difícil valorar totalmente el alcance, pero sobre cuyos resultados se puede hacer un primer balance y extraer algunas lecciones para su eventual redirección. Nuestras primeras aproximaciones al contexto de estudio nos llevan a pensar que los planes de retorno han podido lograr los objetivos gubernamentales, pero no han cubierto necesariamente las expectativas de los propios migrantes. La hipótesis que tratamos de verificar es que este tipo de dispositivos de reinserción laboral tiene un alcance muy limitado y responde, sobre todo, a las necesidades de un perfil reducido de migrantes, excluyendo al grueso de los que salieron y quisieron regresar. Así, y pese a la novedad que supone y al interés que despiertan este tipo de iniciativas, habría que preguntarse si tienen suficientemente en cuenta los múltiples retos que acompañan a los procesos migratorios - donde migración y retorno son entendidos frecuentemente como conceptos estáticos, mostrando una comprensión limitada frente a las complejas realidades de la movilidad - y si los resultados obtenidos permiten pensar que la vía del emprendimiento encierra el potencial esperado.

Como luego detallaremos, al no disponer de datos comparables para el conjunto del país, nuestro estudio se centra específicamente en el caso de los emprendimientos desarrollados por migrantes retornados a las provincias de Ecuador que administrativamente integran la Región 7 (Loja, Zamora y El Oro), al tiempo que trata de delimitar una región que nos permite profundizar en sus dinámicas de desarrollo local y sus vínculos con la migración. En esa zona sur del país, la SENAMI - dependiente del Ministerio de Asuntos Exteriores - apoyó y financió entre los años 2009 y 2013 un total de sesenta y un proyectos de migrantes retornados a las tres provincias ${ }^{5}$. Nuestro interés principal se centra en los casos de los cincuenta y cuatro emprendimientos protagonizados por

4 "Cucayo" es una palabra de origen quichua que significa "comida o provisiones que se llevan en un viaje».

5 Queremos agradecer al personal de la SENAMI en la ciudad de Loja su colaboración y facilidades para acceder a la información sobre el Fondo. 
migrantes ecuatorianos retornados desde los países del Norte afectados por la crisis internacional, especialmente España, junto con los Estados Unidos, Italia e Inglaterra. Estos cuatro países suman más del $80 \%$ de los emprendimientos financiados en la zona de estudio. La revisión manual de los expedientes individuales de los emprendimientos financiados por la SENAMI y la posterior sistematización de la información obtenida - dichos expedientes contienen toda la documentación generada a partir de la selección, implementación y seguimiento de los proyectos -, constituye la base principal en la que se sustenta nuestra argumentación. Complementariamente, dicha labor de archivo se acompañó de la observación sobre el terreno durante una estancia de investigación de seis meses, de las visitas y entrevistas a más de una decena de los emprendimientos financiados que permanecían en funcionamiento en 2014 en la ciudad de Loja y su entorno, así como de las conversaciones informales con migrantes que retornaron y emprendieron al margen del Fondo Cucayo.

\section{EI Fondo Cucayo y la política de retorno en Ecuador}

Ecuador es uno de los pocos países con alta incidencia de la emigración que ha establecido como una de sus prioridades facilitar el retorno de sus ciudadanos en el exterior. Antes de que la crisis económica internacional se hiciera patente, el Estado ecuatoriano ya trabajaba en el diseño de una política de protección de los migrantes y facilitación del retorno. Con el estallido de la crisis en los países de emigración las políticas de retorno tomaron mayor sentido y coincidieron en el inicio de su implementación con la puesta en marcha de dispositivos de incentivación del retorno por parte de algunos de los países en que los migrantes ecuatorianos se hallaban presentes - en el caso de España particularmente a través del Programa PREVIE ${ }^{6}$.

En Ecuador, desde finales de los 1990, y muy especialmente durante el período 2000-2007, se empezaron a generar políticas y directrices que mostraban de manera general la preocupación de la sociedad y de los gobiernos por la cuestión migratoria ${ }^{7}$. Fue a partir del año 2000, dada la notoria presencia internacional de trabajadores ecuatorianos - sobre todo en España - y el impacto de las remesas recibidas en el país, cuando los temas de emigración y ayuda a los emigrantes se situaron en el discurso y en la acción política como temas relevantes. Ya con las elecciones presidenciales de 2007 , en las propuestas de todos los candidatos a la presidencia, la migración y los emigrantes pasan a ser referentes obligatorios de sus planes y ofertas de campaña. Tanto es así que, después de ganar las elecciones, el gobierno de Rafael Correa lidera un cambio en la Constitución de

\footnotetext{
6 Programa de Retorno Voluntario de Inmigrantes desde España, puesto en marcha por el gobierno español.

7 Entre los principales se puede citar: Plan Nacional de Derechos Humanos (Ministerio de Relaciones exteriores, 1998); Plan de Apoyo a los ecuatorianos en el exterior

(Ministerio de Relaciones Exteriores, 2001); Programa de Ayuda, Ahorros e Inversión para los Migrantes ecuatorianos (Ministerio de Relaciones Exteriores, 2002); Plan Operativo de Migrantes Extranjeros y Refugiados (2003-2006); Plan Nacional para combatir la Trata de personas, el tráfico ilegal de migrantes y la explotación sexual y laboral (2006); Plan Nacional de Política Exterior 2006-2020 (Ministerio de Relaciones Exteriores); Plan Ecuador (2007); Plan Nacional de Desarrollo (2007); Plan Nacional de Desarrollo Humano de las Migraciones (SENAMI, 2007); Plan de Acción para el fortalecimiento de la protección de los refugiados en el Ecuador (Ministerio de Relaciones Exteriores, 2008).
} 
2008 e «implementa una política migratoria integral recogida en el Plan Nacional de Desarrollo Humano para las Migraciones, que incluye programas, proyectos y acciones encaminadas a garantizar la protección y el tratamiento integral de la migración, de las personas migrantes, con independencia de su origen y estatus administrativos dentro del territorio de un estado ${ }^{8}$. Este instrumento contempla un conjunto de programas y proyectos que contribuyen al cumplimiento de las metas establecidas en el Plan Nacional de Desarrollo del Gobierno de la Revolución Ciudadana y constituye una respuesta para: 1) Incluir a los ausentes en el conjunto de políticas públicas nacionales; 2) Mitigar los efectos negativos de la migración y brindar una atención integral a las personas migrantes y sus familias y 3) Aprovechar las oportunidades que genera la dinámica migratoria para las personas migrantes, su familia, su entorno y su país (SENAMI, 2007).

En la nueva Constitución de 2008 se reconocen derechos fundamentales de las personas en el exterior y se incorpora el término "movilidad», tratando así de superar la carga peyorativa que acompañaba a la migración en los países receptores. Como muestra de la preocupación que acompaña a este renovado enfoque, mientras que la anterior Constitución ecuatoriana tenía un artículo relacionado con la movilidad, en la actual hay unos cincuenta y siete artículos que conciben el tema de manera integral y transversal, incorporando elementos fundamentales como los conceptos de "refugio" y "tránsito». En función de esta nueva orientación política - que no puede desvincularse de un nuevo proyecto de país que se asocia con una mayor independencia del exterior, incluida la dependencia generada por la misma migración -, la Constitución de 2008 establece en su Artículo 40 que el Estado promoverá los vínculos de los migrantes con Ecuador, facilitará la reunificación familiar y estimulará el retorno voluntario. Por su parte, el Artículo 338 recoge que el Estado promoverá y protegerá el ahorro interno como fuente de inversión productiva en el país y, asimismo, generará incentivos para facilitar el retorno del ahorro y de los bienes de las personas migrantes y para que el ahorro de las personas y de las diferentes unidades económicas se oriente hacia la inversión productiva de calidad.

Asimismo, el Plan Nacional de Desarrollo Humano para las Migraciones 2007-2010 establece entre sus objetivos "alentar la permanencia de los ecuatorianos en su país y construir las condiciones que hagan posible el Retorno Voluntario Digno y Sostenible de las personas emigrantes» (SENAMI, 2007). Este objetivo se concreta en las siguientes políticas: desarrollar un plan de retorno voluntario, digno y sostenible de emigrantes y su reinserción; corregir las desigualdades geográficas a través del mejoramiento de las condiciones de vida, construcción de infraestructuras y oportunidades de empleo con el fin de reducir la propensión a la migración interna e internacional; apoyar a las diferentes entidades estatales en la eliminación de todas aquellas causas económicas, sociales y políticas que provocan la emigración forzada; apoyar en la generación de oportunidades de trabajo a partir de la constitución de un sistema financiero que ayude a las familias de bajos ingresos con el fin de invertir y crear recursos dentro del país y fomentar la valoración del ser y sentirse ecuatoriano.

8 Intervención de la embajadora María Fernanda Espinosa, representante permanente de Ecuador ante Naciones Unidas en Nueva York el 29 de septiembre de 2008. 
En esta línea, el principal instrumento de la política migratoria de Ecuador en relación con su diáspora en el exterior ha sido el Plan Bienvenid@s a Casa. Este plan se diseñó en el año 2007 - justo antes del estallido de la crisis financiera internacional - y engloba tres programas: Programa Vínculos, Programa Volver a Casa y Programa de Incentivos y Orientación a personas migrantes para la Inversión Social y Productiva. Según los datos de la SENAMI, desde finales del 2008 hasta agosto de 2011, 14.623 ecuatorianos habían retornado a Ecuador con ayuda directa del Plan Bienvenid@s a Casa. En ese mismo período, 6.157 personas regresaron al país con menajes de casa y equipo de trabajo exento de impuestos, se otorgaron 1.630 préstamos a través de operadoras financieras calificadas y 4.772 migrantes recibieron capacitación y asesoramiento. Por último, y dentro del tercer programa, dirigido específicamente a fomentar las inversiones de los migrantes retornados, se enmarca el Fondo Concursable Cucayo, del que se beneficiaron un total de 357 emprendimientos en el conjunto del país. Dicho fondo ofrece ayuda económica no reembolsable y apoyo técnico para la puesta en marcha de microempresas que faciliten la reinserción económica de los migrantes retornados.

El Fondo Cucayo estuvo vigente entre los años 2008 y $2012^{9}$ y los proyectos presentados eran susceptibles de recibir un máximo de 15.000 dólares, siendo seleccionados de acuerdo con el tipo de proyecto, la innovación, la factibilidad de su puesta en marcha, la demanda potencial, los fondos disponibles para el financiamiento, la revisión de los perfiles preseleccionados y su evaluación. Tras la selección de los proyectos se establecía un convenio entre el beneficiario y la institución que tenía una vigencia de dos años a partir de la firma, con el compromiso por parte de la institución de otorgar el capital semilla y realizar la asesoría, el acompañamiento y seguimiento del proceso de incubación y el seguimiento y acompañamiento en el proceso de post-incubación ${ }^{10}$.

De modo más detallado, el desarrollo del Fondo involucraba tres etapas: la primera, la convocatoria pública que se realizaba a través de la plataforma virtual de la SENAMI, con una duración de treinta días a partir de la apertura de la misma, y la cumplimentación de un formulario de aplicación en el que se solicitaba información y datos generales del proponente, información migratoria y cuestiones relacionadas con la idea o iniciativa del negocio - el formulario también contenía criterios que evaluaban la experiencia del interesado en la actividad propuesta, así como su capacidad y visión empresarial. La siguiente fase era la de pre-incubación, con varias etapas: recepción de ideas de negocios, selección de ideas de negocios (pre-selección), asignación de mentores externos, elaboración de perfiles de proyectos, evaluación y selección de proyectos por parte del Comité Técnico (a partir de criterios técnicos de rentabilidad y factibilidad), validación de documentos, aprobación de los perfiles por parte del

\footnotetext{
9 Después de 2012 la SENAMI dejó en suspenso nuevas convocatorias del Fondo, aunque los emprendimientos ya financiados siguieron su camino a la espera de una evaluación de conjunto y la toma de una decisión política sobre su futuro. En cuanto a la SENAMI, esta también fue objeto de reestructuración en 2013 y su personal fue absorbido por el Ministerio de Asuntos Exteriores, aunque su estatus sigue siendo en la actualidad incierto.
}

10 Una novedad importante en la convocatoria del año 2012 es que si el perfil de proyecto no era seleccionado, la SENAMI orientaba la propuesta de emprendimiento hacia entidades de la Banca Pública para una posible tramitación de crédito. 
Comité Ejecutivo, firma de convenios y transferencia de capital semilla. Por último, la tercera fase era la de incubación, que consistía en el apoyo y asistencia técnica por parte de mentores externos, para que los beneficiarios pusieran en marcha sus negocios. Los mentores eran profesionales especialistas en gestión de proyectos y gestión empresarial contratados externamente por la SENAMI y ofrecían asistencia en las áreas de gestión de productividad, gestión de calidad, análisis financiero, recursos humanos, mercadeo, entre otros. Este acompañamiento se realizaba por un período de entre seis y ocho meses, tiempo durante el cual la Secretaría hacía un seguimiento a través del contacto tanto con ellos como con los beneficiarios (Moncayo y Herrera, 2011).

\section{El contexto del retorno: las provincias del Sur de Ecuador}

El perfil migratorio de Ecuador publicado en 2012 por la Organización Internacional para las Migraciones afirmaba que: "La combinación del crecimiento económico y el aumento del gasto social presumiblemente repercutieron en la disminución tanto de la pobreza, como de la desigualdad en la década. Así, la pobreza urbana era del $26,3 \%$ en 2006 y bajó al 17,4\% en 2009. La pobreza rural disminuyó en diez puntos entre 2006 y 2009 ».

Sin embargo, el informe destaca cómo «una de las zonas del país desde donde sigue saliendo población al extranjero son las áreas rurales del sur del país, zonas que ya cuentan con una tradición migratoria anterior, en donde las condiciones de pobreza se entremezclan con la existencia de redes sociales que facilitan la salida" (OIM, 2012: 32). Son precisamente estas provincias del Sur de Ecuador (Loja, Zamora y El Oro) las que constituyen la región en la que se implementaron los emprendimientos que analizamos en este artículo y el lugar al que retornaron los migrantes que los protagonizan.

La Región 7 cuenta con una extensión de $27.441 \mathrm{~km}^{2}$ (el equivalente al $11 \%$ de la superficie nacional, véase Mapa 1) y una población, en 2010, de 1.141.001 habitantes (un $8 \%$ del total nacional). Sin embargo, y a pesar de que las tasas de fecundidad en las tres provincias son superiores al promedio nacional (véase Tabla 1), su participación en el número de habitantes a nivel nacional durante las tres últimas décadas ha disminuido, lo que supone un claro indicador de la constante migración de los originarios de esta zona hacia otras regiones de Ecuador y, en menor medida, hacia el exterior del país.

La Región 7 tiene como característica particular el hecho de que está integrada por tres provincias cuyos territorios se ubican en distintas regiones naturales: El Oro está en la Costa, Loja en la Región Interandina y Zamora Chinchipe en la Amazonía. Sus características geográficas han generado dinámicas diferenciales a nivel económico y de movilidad en las tres provincias. En el caso de El Oro, su participación en la economía nacional se justifica en el hecho de que, como provincia costera, ha contado con ventajas competitivas, tales como su salida al mar a través de Puerto Bolívar y su importante relación de intercambio comercial con el Perú. Además, los cultivos de banano, café, cacao y otros productos primarios conjuntamente con el desarrollo de la industria del camarón han permitido que esta provincia reciba flujos migratorios internos de otras 


\section{Mapa 1: Regiones de Ecuador}

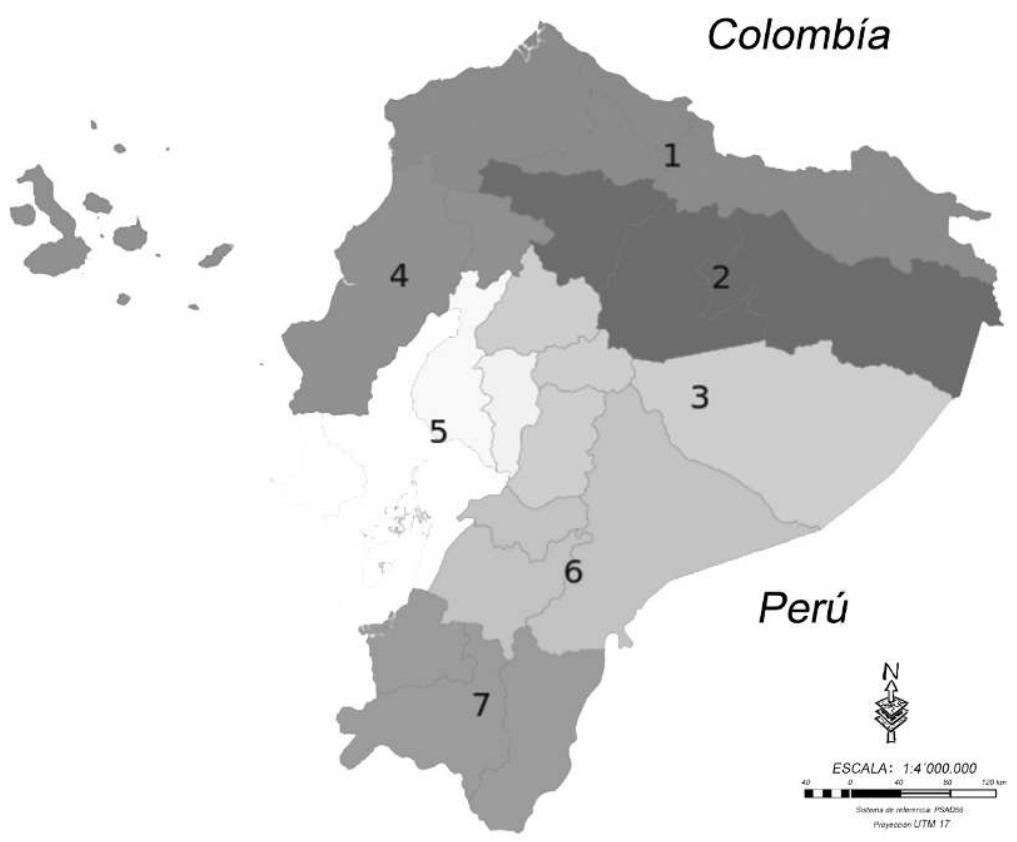

Región 1: Esmeraldas, Carchi, Imbabura y Sucumbíos; Región 2: Pichincha, Napo y Orellana; Región 3: Chimborazo, Tungurahua, Pastaza y Cotopaxi; Región 4: Manabí, Galápagos y Santo Domingo de los Tsachilas; Región 5: Santa Elena, Guayas, Los Ríos y Bolívar; Región 6: Cañar, Azuay y Morona Santiago;

Región 7: El Oro, Loja y Zamora Chinchipe Fuente: R. Correa y S. Ochoa.

Tabla 1: Participación de las provincias de la Región 7 en el total nacional de la población (en \%)

\begin{tabular}{lccc}
\hline & 1990 & 2001 & 2010 \\
\hline El Oro & 4,3 & 4,3 & 4,1 \\
Loja & 4,0 & 3,3 & 3,1 \\
Zamora & 0,7 & 0,6 & 0,6 \\
\hline
\end{tabular}

Fuente: Censo Nacional del Ecuador, INEC (1990, 2001 y 2010). 
provincias y que su constante tasa de crecimiento poblacional tenga tendencia a mantenerse a lo largo del tiempo. En el caso de la provincia de Loja, la combinación de una topografía accidentada, la baja productividad de la agricultura y un débil sector industrial la han convertido en una región con menores niveles de desarrollo, en cuya economía predominan las actividades de comercio y servicios. Sumado todo a ello a la desatención padecida por los sucesivos gobiernos centrales, el resultado ha sido una fuerte emigración (interna e internacional) de sus naturales. En Zamora Chinchipe se repiten algunas características de la provincia de Loja, aunque la primera fue hace medio siglo una zona de colonización, debido a un proceso de políticas públicas que buscaban ocupar y aprovechar sus territorios. Esta última provincia, provista de una enorme biodiversidad, es también rica en recursos minerales, con proyectos extractivos a gran escala en curso o proyectados como el proyecto Mirador.

Al considerar los datos del VAB de las tres provincias se observa (Tabla 2) que su participación en el VAB total de Ecuador no llega al 6\%, la dependencia del comercio y servicios es notoria y no existe actividad industrial que pueda generar sinergias y externalidades en torno a ella. Esto produce un círculo perverso ocasionado, en primer lugar, por la falta de políticas públicas que coadyuven a mejorar condiciones para el crecimiento, sumado a la poca rentabilidad y a los bajos salarios en las actividades agropecuarias, a la falta de generación de empleo por parte de un sector manufacturero incipiente y a la inserción de la mayoría de la población en actividades comerciales y de servicios, lo que genera, a su vez, una significativa propensión a emigrar entre la población en edad laboral.

De acuerdo con los indicadores que constan en la Tabla 3 la situación social y económica es relativamente homogénea para las tres provincias de la Región 7, aunque con algunos matices - la provincia de El Oro aparece con una situación algo más favorable que las de Loja y Zamora. En cambio, en relación con la situación nacional, los datos de subempleo y pobreza son superiores a la media, al mismo tiempo que la fecundidad es mayor y los años de escolaridad inferiores a los del conjunto del país. Las tasas de fecundidad, que se ubican por encima del promedio nacional, podrían ser positivas desde un punto de vista a medio y largo plazo con población joven y en edades productivas. Sin embargo, dadas las actuales condiciones de la zona de estudio (falta de fuentes de trabajo, subempleo y pobreza) se tiende a incrementar la dependencia demográfica y la responsabilidad y necesidad de los jefes y jefas de hogar a la hora de mejorar sus perspectivas laborales y salariales, provocando la búsqueda de nuevas oportunidades en otros lugares. En este mismo contexto, el crecimiento de la población de edades laborales podría ofrecer la posibilidad de aumentar el capital humano y, por ende, mejorar la producción y la economía a través de su adecuada y progresiva incorporación al mercado de trabajo. No obstante, sin la generación de nuevos puestos y empleo adecuado, especialmente entre una población con niveles de estudio medios, la única alternativa parece ser la emigración.

Como resultado de estos determinantes, las tres provincias de la Región 7 han sido tradicionalmente emisoras de emigrantes nacionales e internacionales - según el Censo Nacional, en 2010 se encontrarían residiendo en el exterior 26.469 personas provenientes de la Región 7 -, aunque la presión 
Tabla 2: Valor Agregado Bruto (VAB) de las provincias de la Región 7 (2009)

\begin{tabular}{|c|c|c|c|c|c|c|}
\hline & & Primario & Secundario & Terciario & Total & $\begin{array}{c}\text { Participación } \\
\text { del total } \\
\text { nacional (\%) }\end{array}$ \\
\hline El Oro & $\begin{array}{l}\$ \\
\%\end{array}$ & $\begin{array}{c}571.662 \\
28\end{array}$ & $\begin{array}{c}59.526 \\
3\end{array}$ & $\begin{array}{c}1.422 .066 \\
69\end{array}$ & $\begin{array}{c}2.053 .254 \\
100\end{array}$ & 3,5 \\
\hline Loja & $\begin{array}{l}\$ \\
\%\end{array}$ & $\begin{array}{c}172.523 \\
15\end{array}$ & $\begin{array}{c}36.204 \\
3\end{array}$ & $\begin{array}{c}967.487 \\
82\end{array}$ & $\begin{array}{c}1.176 .214 \\
100\end{array}$ & 2 \\
\hline Zamora & $\begin{array}{l}\$ \\
\%\end{array}$ & $\begin{array}{c}27.761 \\
14\end{array}$ & $\begin{array}{c}1.992 \\
1\end{array}$ & $\begin{array}{c}174.863 \\
85\end{array}$ & $\begin{array}{c}204.616 \\
100\end{array}$ & 0,3 \\
\hline
\end{tabular}

Fuente: Cuentas Provinciales. Banco Central del Ecuador (2013).

Tabla 3: Indicadores socio-económicos de las provincias de la Región 7

\begin{tabular}{lcccccc}
\hline & $\begin{array}{c}\text { Tasa de } \\
\text { fecundidad }\end{array}$ & $\begin{array}{c}\text { Años de } \\
\text { escolaridad }\end{array}$ & $\begin{array}{c}\text { Desem- } \\
\text { pleo }^{* * *}\end{array}$ & $\begin{array}{c}\text { Subem- } \\
\text { pleo }^{* * * *}\end{array}$ & $\begin{array}{c}\text { Pobreza } \\
\text { NBI }^{* * * * *}\end{array}$ & $\begin{array}{c}\text { Desigualdad } \\
\text { por } \\
\text { consumo }^{* * * * *}\end{array}$ \\
\hline El Oro & 2,5 & 10,2 & 3,3 & 63 & 61,2 & 0,388 \\
Loja & 3,2 & 10,2 & 5 & 75 & 61,8 & 0,482 \\
Zamora & 3,9 & 9,5 & 3,3 & 76,4 & 73,8 & 0,511 \\
$\begin{array}{l}\text { Promedio } \\
\text { nacional }\end{array}$ & 2,4 & 10,4 & 4,2 & 53,7 & 60,1 & 0,456 \\
\hline
\end{tabular}

* Encuesta Nacional de Salud y Nutrición, ENSANUT (2012). Demografía, salud materna e infantil y salud sexual y reproductiva. Datos provinciales (2007-2012).

** Censo Nacional del Ecuador, INEC (2010).

*** Encuesta Urbana de Empleo y Desempleo, INEC (2013).

Tasa de subempleo. Agendas para la transformación productiva Territorial (2011). ***** Pobreza por Necesidades básicas insatisfechas (NBI) y Coeficiente de Gini. Encuesta de Condiciones de Vida, INEC (2006).

Fuente: SIISE (Sistema de Indicadores Sociales del Ecuador).

Tabla 4: País de residencia de los emigrantes de la Región 7 (2010) (en efectivos)

\begin{tabular}{lcccccc}
\hline & España & EEUU & Italia & Inglaterra & Otros & Total \\
\hline El Oro & 7.979 & 1.327 & 2.698 & 22 & 1.503 & $\mathbf{1 3 . 5 2 9}$ \\
Loja & 7.688 & 1.575 & 381 & 136 & 1.066 & $\mathbf{1 0 . 8 4 6}$ \\
Zamora & 1.477 & 393 & 41 & 4 & 179 & $\mathbf{2 . 0 9 4}$ \\
Total & 17.144 & 3.295 & 3.120 & 162 & 2.748 & $\mathbf{2 6 . 4 6 9}$ \\
\hline
\end{tabular}

Fuente: Censo Nacional del Ecuador, INEC (2010). 
migratoria se ha reducido notablemente en la última década - si se calcula que, en 2001, salieron 7.257 personas desde las tres provincias, en 2010 lo hicieron 3.207, según los datos censales del INEC. En cuanto a los destinos, si antes del año 2000 Estados Unidos era el país de preferencia para los migrantes, la crisis económica de 1999 transformó el comportamiento socioeconómico de la población generando nuevas estrategias familiares para sobrellevar el deterioro la situación, ocasionándose un proceso emigratorio con destinos más diversificados, orientado principalmente hacia España e Italia (véase Tabla 4). La necesidad de mano de obra barata en Europa y la falta de articulación y de desarrollo en las economías locales fueron las causas fundamentales de que la población haya migrado en busca de mejores oportunidades y expectativas de vida en el exterior de la región (Correa, 2013).

El perfil de la emigración internacional de la Región 7 es predominantemente urbano y masculino, de modo que, para el caso de las provincias de Loja y Zamora, de cada diez emigrantes internacionales seis son hombres y cuatro mujeres; una diferencia que es, no obstante, menor entre la población emigrante masculina y femenina de El Oro. La edad de la gran mayoría, tanto de los hombres como las mujeres de esta región que han migrado, está concentrada en edades centrales. Para las tres provincias, el grupo de hombres y mujeres de entre quince y cuarenta y cinco años no es menor en ningún caso al $80 \%$ del total de la estructura etaria. Tal y como indican Ramírez y Ramírez (2005), de acuerdo con las edades de los emigrantes se trata de una migración que concentra a población joven, siendo la mayoría de estos, los hijos mayores de la familia nuclear o uno de los cónyuges.

Tabla 5: Relación población emigrante/población total en la Región 7 (en \%)

\begin{tabular}{|c|c|c|c|c|}
\hline & \multicolumn{3}{|c|}{$\begin{array}{l}\text { Población migrante internacional/ } \\
\text { Población total }\end{array}$} & \multirow{2}{*}{$\begin{array}{c}\text { Migrantes } \\
\text { retornados entre } \\
2005-2010 \\
\text { (en efectivos) }\end{array}$} \\
\hline & 2001 & 2010 & Diferencia & \\
\hline El Oro & 4,29 & 2,25 & $-2,04$ & 4.664 \\
\hline Loja & 5,97 & 2,42 & $-3,55$ & 6.784 \\
\hline Zamora & 5,57 & 2,29 & $-3,28$ & 956 \\
\hline
\end{tabular}

Fuente: Censo Nacional del Ecuador, INEC (2001 y 2010).

Como venimos diciendo, la dinámica migratoria se transformó en los últimos diez años y, como puede verse en la Tabla 5, en el período intercensal 2001-2010, la población que se encontraba en el exterior disminuyó en las tres provincias, mientras que, durante el período 2005-2010, 12.404 migrantes habrían retornado desde el exterior, según las estimaciones del INEC.

También las remesas acusaron un importante descenso en el período entre 2007 y 2013 (véase Tabla 6), en paralelo a la disminución de las salidas y el incremento de los retornos. De este modo, de manera particular las remesas en Zamora decrecieron en un $79 \%$, mientras que para Loja esta disminución fue del $71 \%$ y en El Oro se evidenció que las familias de esta provincia recibieron un $42 \%$ menos. Esta volatilidad en las remesas y el reducido tamaño, la débil estructura y la escasa diversificación de las economías de las regiones con un 
alto grado de dependencia ${ }^{11}$ de las remesas - sobre todo en Loja - ha ocasionado una severa contracción del consumo, que afecta a todos los sectores en detrimento de su economía y bienestar social.

Tabla 6: Remesas recibidas en la Región 7 (2007-2013) (en miles de dólares)

\begin{tabular}{lccc}
\hline Año & El Oro & Loja & Zamora \\
\hline 2007 & $281.111,0$ & $150.098,4$ & $38.176,7$ \\
2008 & 182.109 .9 & $139.614,7$ & $12.563,7$ \\
2009 & 123.182 .2 & $99.921,6$ & $7.593,6$ \\
2010 & $100.506,3$ & $87.563,5$ & $6.577,3$ \\
2011 & $103.808,7$ & $95.150,3$ & $8.574,4$ \\
2012 & $93.536,1$ & $88.787,08$ & 10.291 .1 \\
2013 & $82.066,9$ & $87.146,5$ & $7.992,2$ \\
\hline
\end{tabular}

Fuente: Estadística de Remesas, Banco Central del Ecuador (2013).

\section{Los resultados de la implementación del Fondo Cucayo}

La implementación del Fondo Cucayo en la Región 7 benefició entre los años 2008 y 2012 a un total de sesenta y un emprendimientos. Tomando los datos de los cuatro países seleccionados para nuestro artículo (España, Estados Unidos, Italia e Inglaterra), que afectan a cincuenta y cuatro casos ${ }^{12}$, obtenemos una serie de evidencias relativas tanto a los beneficiarios como a sus emprendimientos.

En primer lugar, atendiendo a la nacionalidad, los emprendimientos analizados financiados por el Fondo Cucayo en la Región 7 corresponden en su gran mayoría a migrantes retornados desde España - treinta y siete casos, que representan el $69 \%$ del total -, frente a ocho retornados desde Estados Unidos, cinco desde Italia y cuatro desde Inglaterra - el resto de los emprendedores no incluidos aquí retornaron desde Venezuela, Chile, Colombia e Israel. Esta distribución territorial de los retornados se corresponde en buen grado con el peso de los migrantes en los países de emigración, aunque proporcionalmente hubo menos retornos desde países como Italia, a la vez que desconocemos la incidencia de las re-emigraciones - en el caso de Loja pudimos constatar sobre el terreno la existencia de casos de re-emigración desde Italia a Inglaterra.

Por sexos, los emprendimientos se corresponden en su mayor parte con hombres (treinta y siete casos), frente a los emprendimientos femeninos (diecisiete casos). Sin embargo, y a pesar de que el número de emprendedores

11 Para el 2007 la relación Remesas/VAB fue para Loja el 41\%, Zamora 16\% y El Oro 9\% Para 2013 esta relación es para Loja 10\%, Zamora 5\% y El Oro 4\%. De acuerdo con el censo de 2010, el $8.4 \%$ de los hogares de El Oro, el $8.2 \%$ de los de Loja y el $7.9 \%$ de los de Zamora eran receptores de remesas.

12 Los casos analizados en nuestra investigación representan el 88,5\% de los sesenta y un emprendimientos financiados en la Región 7 y el 15\% del total de 357 emprendimientos financiados en el conjunto del país entre 2008 y 2012. 
hombres duplica al de mujeres, la diferencia entre hombres y mujeres emigrados desde la región no resulta tan elevada. La diferencia es especialmente relevante en el medio urbano, donde, en ciudades como Loja, la emigración femenina ha sido especialmente intensa hacia España y orientada hacia el servicio doméstico y los cuidados personales. Pese a la incidencia de la emigración femenina, las mujeres retornadas contactadas durante nuestra investigación expresaban encontrarse con mayores barreras que los hombres a la hora de emprender un negocio, destacando en especial la incomprensión encontrada en el medio local, así como los requerimientos de los parientes para hacerse cargo de las responsabilidades y tareas familiares, incluido el cuidado de los hijos que quedaron en Ecuador al emigrar.

Por edades, el grupo más numeroso de los beneficiarios se concentra en la franja de edad de entre treinta y cuarenta años, con veinticuatro casos, mientras que entre los cuarenta y uno y cincuenta años el número se reduce a catorce $y$, entre los cincuenta y uno y sesenta años, a trece. Asimismo, los mayores de sesenta años solo son tres y no existe ningún caso de beneficiario menor de treinta años. Dicha distribución, que deja fuera a los más jóvenes, parece coherente con los largos períodos de tiempo pasados en el exterior por los migrantes, como ahora veremos, y sus edades a la hora del retorno.

En cuanto a los años de estancia en el extranjero, más de la mitad de los beneficiarios permanecieron entre seis y diez años (veintinueve casos) y catorce de ellos entre once y quince años. Por encima de los quince años solo figuran dos casos y, por debajo de los cinco años, el número de casos es de seis. Los hombres estuvieron un promedio de 9,8 años en el exterior, mientras que las mujeres permanecieron un promedio de 7,4 años. Por países, la mayor duración de la emigración corresponde a Italia (10,8 años), seguida de España $(8,9)$, Estados Unidos $(8,8)$ e Inglaterra $(8,5)$. La mayor diferencia entre hombres y mujeres según los países de emigración se muestra en Inglaterra (10,6 años para los hombres y 2 para las mujeres), mientras que la mayor igualdad se da en el caso de España, con un año de diferencia entre ambos, pero siendo el único país de los cuatro en el que la duración de la estancia de las mujeres supera a la de los hombres. La diferencia tan desigual en las estancias de hombres y mujeres en ambos países puede explicarse por las características de los proyectos migratorios: migración individual en el caso de Inglaterra, frente a la migración más familiar en el caso de España.

Si nos referimos al año de salida de Ecuador, prácticamente la mitad de los beneficiarios lo hicieron entre los años 1999 y 2000, coincidiendo con el impacto de la dolarización - los entrevistados siguen refiriéndose a la pérdida de negocios, viviendas y ahorros que les impulsaron a abandonar el país. Por otra parte, el período de los años 2008 a 2010 concentra el grueso del retorno de los beneficiarios (cerca de un $80 \%$ de ellos), coincidiendo con los años de mayor impacto de la crisis internacional. 
Gráfico 1: Duración de la migración por país y sexo (en años)

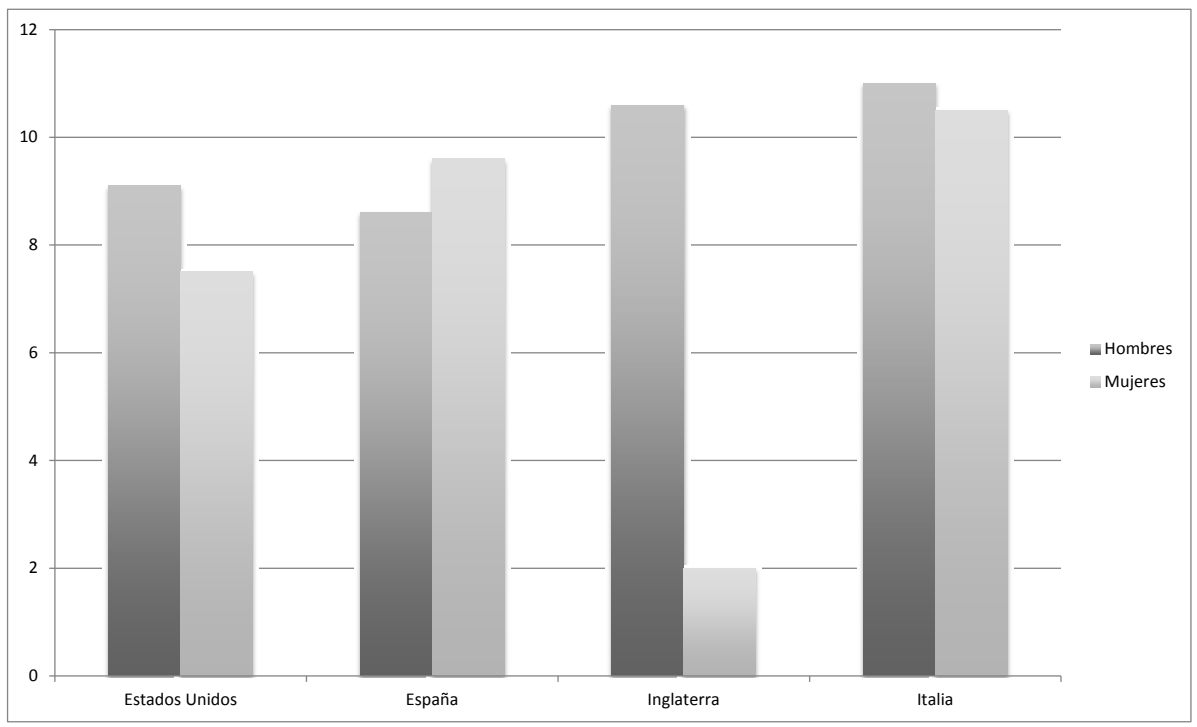

Fuente: Explotación de la base de datos de la SENAMI.

El nivel de estudios con mayor representación entre los beneficiarios de los que se dispone de este dato son los estudios universitarios (veinte casos), seguido de los estudios de bachiller (dieciocho casos) y los estudios primarios (siete casos), lo que representa en conjunto un elevado nivel de estudios potencialmente beneficioso para la inversión de capital humano. La acumulación de capital educativo podría resultar, en principio, positiva para los nuevos emprendimientos, aunque esta cuestión haya planteado dudas en diferentes estudios (Nieto, 2012). De igual modo, y como veremos más adelante, ocurre con la posibilidad de que la formación y experiencias adquiridas en el exterior puedan transferirse en el nuevo contexto resulta problemática. A este respecto, nuestra observación sobre el terreno nos permitió constatar la existencia de niveles de estudio medio-altos entre un buen número de los retornados que pusieron en marcha emprendimientos, pero con estudios no relacionados con las actividades iniciadas.

Si relacionamos el nivel estudios con los países de emigración, podemos ver que el $75 \%$ de los que emigraron a Estados Unidos cuenta con estudios superiores, frente al $32 \%$ de los que lo hicieron a España, el $25 \%$ de los que fueron a Inglaterra y el $20 \%$ de los que emigraron a Italia. Los estudios de bachillerato son los más comunes entre los que emigraron a Italia (40\%) y España (38\%), mientras que en el caso de Inglaterra los estudios se reparten por igual entre los diferentes niveles. En este apartado es destacable el caso de los elevados niveles de estudios de los retornados desde Estados Unidos, aunque sus negocios no se corresponden con sus cualificaciones (un taller de coches, una granja de cerdos, una cafetería o una panadería). 
Gráfico 2: Nivel de estudios por país (en \%)

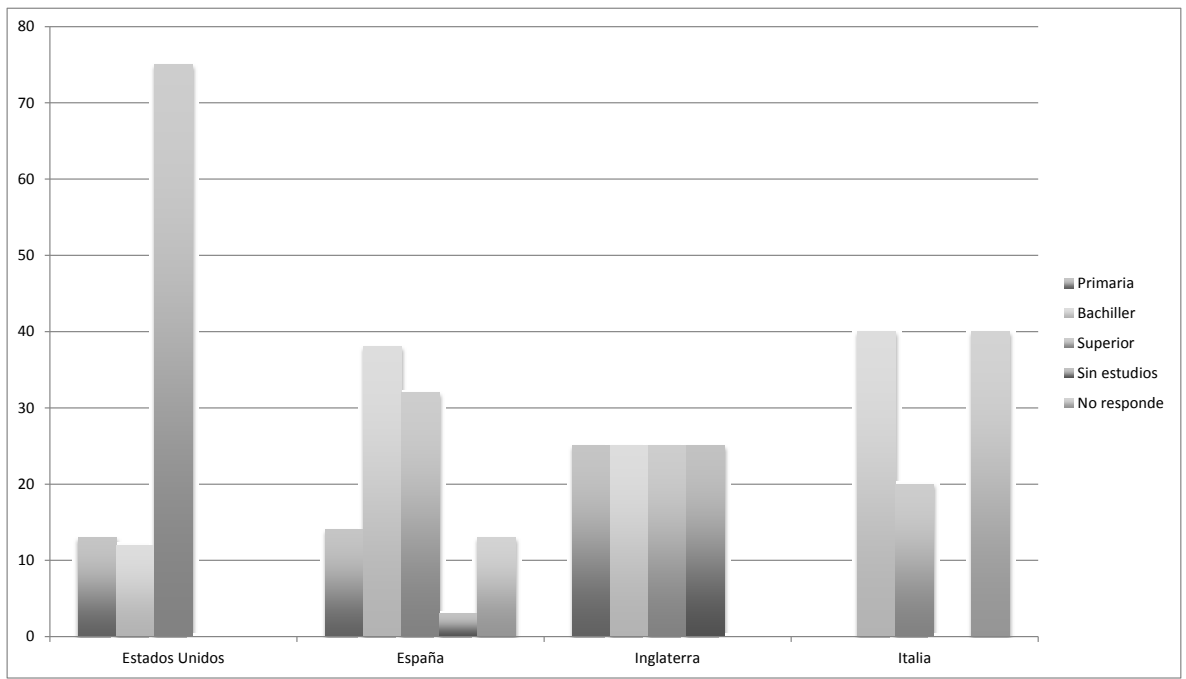

Fuente: Explotación de la base de datos de la SENAMI.

Respecto a los emprendimientos, en treinta y ocho de los casos se trata de nuevos negocios y, en dieciséis, de ampliaciones de negocios ya existentes - el Fondo también ofrecía la posibilidad de solicitar financiación en este último caso. Los negocios ampliados, habitualmente tras haber sido mantenidos por familiares de los retornados durante su ausencia, son los que gozan de una mayor solidez y mayores perspectivas de continuidad, de acuerdo con nuestras propias observaciones. Es el caso, por ejemplo, de una imprenta familiar ampliada con un nuevo local y dotada de nueva maquinaria por un migrante retornado a Loja desde España, donde aprovechó para aprender nuevas técnicas de impresión en su tiempo libre tras su jornada de trabajo en la hostelería.

Los cincuenta y cuatro emprendimientos recibieron un monto total de financiamiento de 740.283 dólares: del total del monto invertido en la provincia de Loja se destinaron 438.283 dólares, en la provincia de El Oro 164.900 dólares y en la de Zamora 137.00 dólares. De igual modo, su distribución es desigual territorialmente y por provincias la que cuenta con mayor número de emprendimientos es Loja (treinta y tres casos), seguida de Zamora (once casos) y El Oro (diez casos). En este sentido hay que destacar que El Oro recibió un monto superior a Zamora, pese a contar con menor número de emprendimientos, lo que se relaciona con el carácter más urbano de los emprendimientos en el primer caso y su mayor coste. También debemos reseñar que sólo la ciudad de Loja (el principal centro urbano de la región) concentra más de un tercio del total de los emprendimientos, de manera que el $56 \%$ de los emprendimientos se desarrollan en el ámbito urbano y el $44 \%$ en el ámbito rural. Así, en las zonas urbanas predominan las inversiones en emprendimientos del sector de los hoteles y restaurantes (37\%), mientras que en las zonas rurales son mayoritarias las inversiones en la agricultura, ganadería, silvicultura y pesca (46\%). 
En cuanto al tipo de emprendimientos la mayor parte de ellos corresponden al sector de los hoteles y restaurantes (diecisiete casos), seguido de la industria y manufactura (catorce casos) ${ }^{13}$, la agricultura, ganadería, silvicultura y pesca (doce casos) ${ }^{14} \mathrm{y}$, por último, los servicios comunitarios, personales y sociales (diez casos) ${ }^{15}$. Esta distribución muestra que una gran parte de los emprendimientos se desarrollan en sectores tradicionales que acusan una cierta saturación (los casos especialmente de la hostelería y la restauración) y donde el margen de innovación resulta menor al de otros sectores (es el caso de los servicios, comunitarios, personales y sociales). De hecho, en las conversaciones mantenidas con emprendedores retornados - pese a ser un sector claramente saturado en ciudades como Loja o Machala - se hacía alusión a la mayor facilidad para iniciar negocios en el sector de la restauración, dada la menor necesidad de formación y capital. En esta línea, el sector que concentra un mayor número de mujeres es el de los hoteles y restaurantes (38\%), seguido de los servicios comunitarios, personales y sociales (31\%). En el caso de los hombres, en cambio, el sector con mayor presencia es el de la agricultura, ganadería, silvicultura y pesca $(30 \%)$, seguido de los hoteles y restaurantes y de la industria y manufactura (ambos con un 27\%). En cualquier caso también hay que tener en cuenta que muchas mujeres que emigraron a España o Italia trabajaron en la hostelería y en los cuidados personales, mientras que muchos de los hombres encontraron empleo en la agricultura y en la construcción - buena parte de las empresas de manufacturas están relacionadas con el sector de la construcción, dedicadas a la fabricación de bloques o estructuras metálicas.

Por niveles de estudios, el mayor porcentaje de migrantes retornados con estudios superiores desarrolla sus emprendimientos en el sector de los hoteles y los restaurantes (40\%), mientras que, entre aquellos con estudios de bachiller, el mayor porcentaje corresponde al sector de la agricultura, ganadería, silvicultura y pesca $(33 \%)$ y en el caso de los retornados con estudios primarios el sector de mayor incidencia es, en cambio, el de los servicios comunitarios, personales y sociales $(43 \%)$.

La relación entre niveles de estudio y tipo de emprendimientos nos conduce nuevamente a dudar sobre las posibilidades de que el capital educativo revierta en la posibilidad de innovar en sectores donde se puede generar un mayor valor añadido. De todos modos, algunos de los retornados con estudios superiores en el sector de la restauración también pusieron en marcha restaurantes que trataban de alejarse de los modelos locales, con decoraciones y menús más próximos a los países de emigración. Al mismo tiempo, resulta destacable que aquellos retornados con menor nivel de estudios apostaran por emprendimientos menos "clásicos», como el caso de una cancha deportiva sintética o una ludoteca.

13 Los más habituales son pequeñas empresas en los sectores de la construcción, el textil y la carpintería.

14 En su mayor parte se trata de explotaciones ganaderas para la cría de cerdos o la producción de leche.

15 Entre ellos se incluye la construcción de una ludoteca, una guardería o una cancha deportiva, así como pequeñas empresas con vocación de servicio comunitario vinculadas a la promoción cultural (producción audiovisual), la mejora ambiental (reciclaje de neumáticos) o la salud (una clínica dental). 
Gráfico 3: Emprendimientos por sector y sexo (en efectivos)

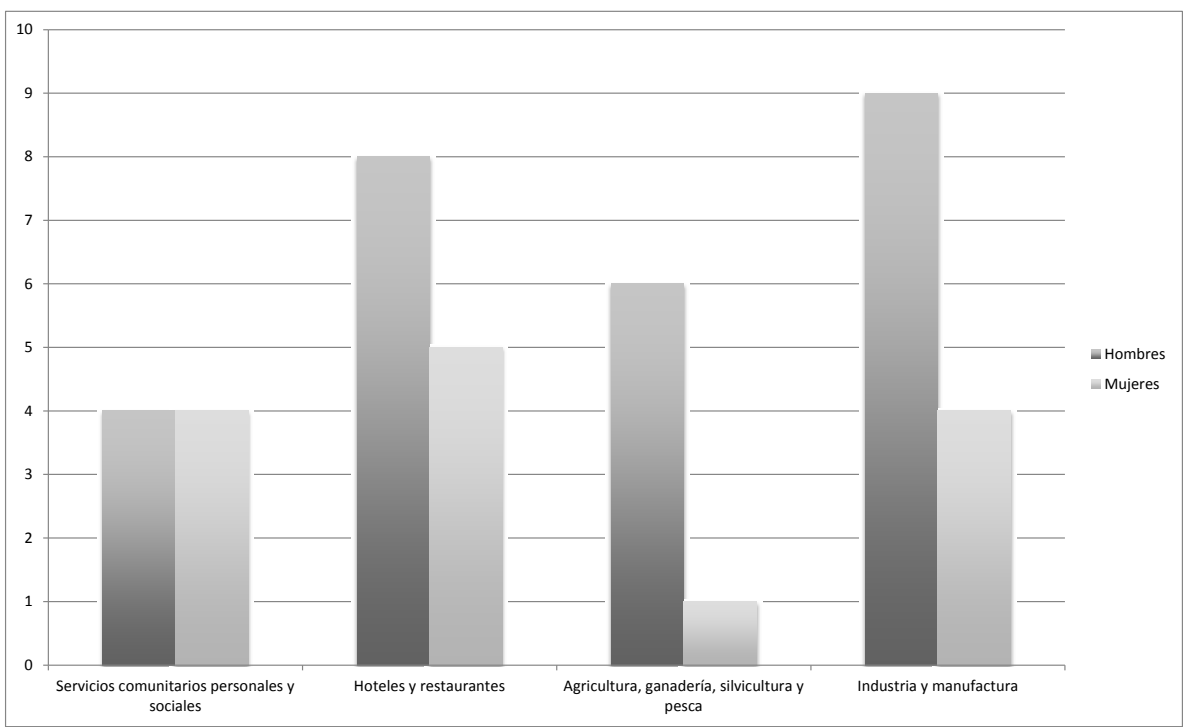

Fuente: Explotación de la base de datos de la SENAMI.

En relación con su impacto económico, los emprendimientos recibieron una media de capital semilla de 11.939 dólares, sobre los 15.000 dólares que podían recibir como máximo. La media de ingresos mensuales que vienen produciendo los emprendimientos es de 858 dólares por negocio, pero resulta claramente favorable a los hombres, con 946 dólares, frente a los 667 dólares de las mujeres, aunque en ambos casos los emprendedores entrevistados coincidían en destacar la insuficiencia de dichos ingresos y, sobre todo, la disminución de ingresos respecto a los salarios obtenidos durante la emigración - muchos de los retornados mantienen el discurso de que ahora "trabajan más y ganan menos".

En cuanto a su impacto laboral, los emprendimientos financiados en la Región 7 generaron en total ciento treinta y seis empleos, duplicando prácticamente el número de hombres (noventa) al de mujeres empleadas (cuarenta y seis). El mayor número de empleos se generó en el sector de los hoteles y restaurantes (cuarenta y siete empleos), seguido de la industria y manufacturas (cuarenta empleos), los servicios comunitarios, personales y sociales (treinta y siete empleos) y la agricultura, ganadería, silvicultura y pesca (doce empleos), con un promedio de tres empleos en todos los sectores, salvo en este último, donde el promedio fue de un empleo por emprendimiento. No obstante, hay que decir que la media de empleo proyectado inicialmente fue de cinco empleos por negocio, mientras que la media real de empleo se situó finalmente en dos empleados en el caso de los afiliados al IESS ${ }^{16}$ y un empleado en el caso de los no afiliados. De hecho, cuatro de los negocios no han generado ningún

16 Instituto Ecuatoriano de Seguridad Social. 
empleado afiliado al IESS, veintiséis de ellos generaron entre uno y cinco empleados afiliados y solo cuatro negocios superaron los cinco empleados afiliados. Estos datos muestran la dificultad para crear nuevos empleos al margen del auto-empleo de los retornados, limitados por su falta de experiencia previa, con pequeños negocios y en sectores con una fuerte competencia.

Gráfico 4: Empleos por sector (en efectivos)

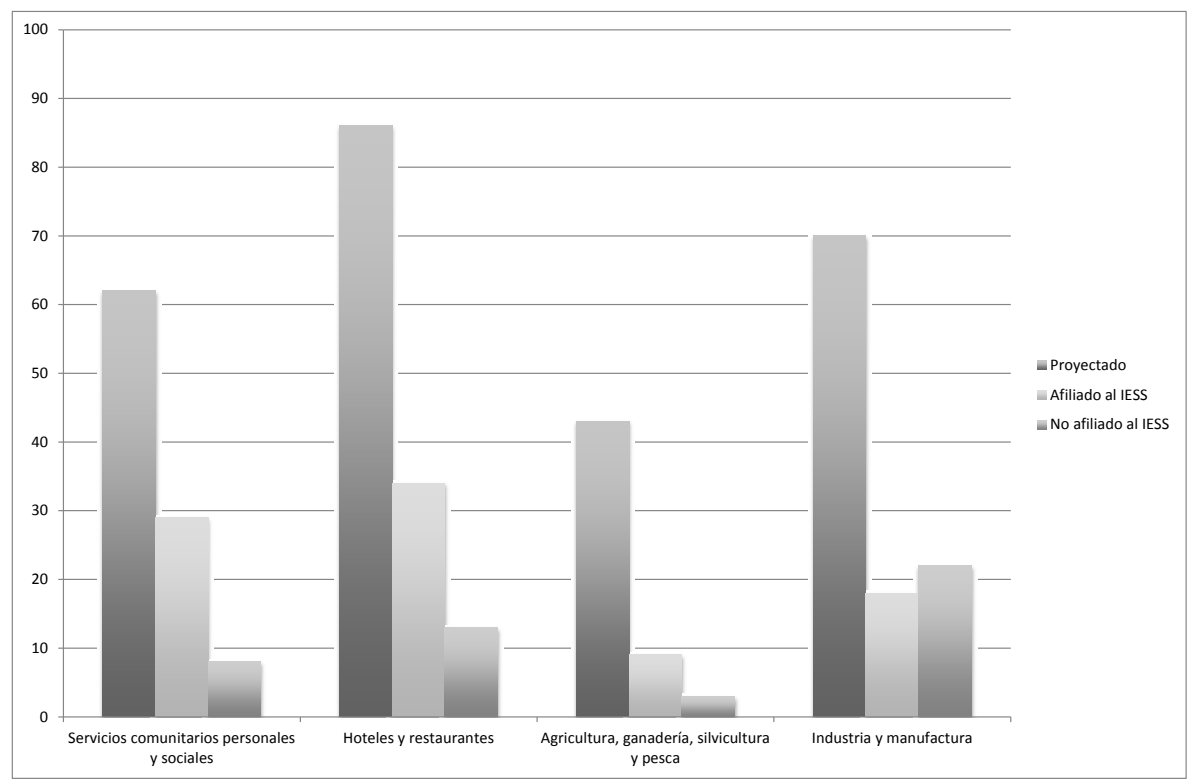

Fuente: Explotación de la base de datos de la SENAMI.

Si hablamos del éxito de los emprendimientos, veintiocho de los cincuenta y cuatro negocios (poco más de la mitad) se encontraban en pleno funcionamiento en julio de 2014 (dos de ellos tras un cambio de actividad), mientras que diecisiete estaban en fase de implementación y nueve de ellos habían cerrado. El elevado número de emprendimientos en fase de implementación aquellos que todavía no han dejado de estar bajo la supervisión del personal de la SENAMI - es un indicador de la complejidad de los trámites a los que se enfrenta la apertura de los negocios y las dificultades para alcanzar su plena autonomía. En cuanto a los emprendimientos que cerraron, la mayor parte de ellos lo hicieron debido a dificultades en el pago de los alquileres de locales, a los escasos beneficios obtenidos o por problemas personales que imposibilitaron hacerse cargo de los negocios. En cualquier caso, si atendemos al sexo de los emprendedores, un $22 \%$ de los emprendimientos regentados por hombres cerraron, frente a sólo un $6 \%$ en el caso de las mujeres - en las conversaciones mantenidas con los emprendedores las mujeres parecían más dispuestas a continuar con los negocios pese a las escasas ganancias, cosa que no ocurría en el mismo grado con los hombres; ello podría ayudar a explicar el mayor número de cierres masculinos. En cambio, el éxito de los emprendimientos no parece tener relación con la zona en la que se instalaron, pues tanto en el ámbito urbano como rural se cerraron el $17 \%$ de los emprendimientos. 


\section{Discusión de los resultados}

El análisis de los principales resultados de la implementación del Fondo Cucayo en las provincias del Sur de Ecuador proyecta un escenario complejo, con éxitos y fracasos en los emprendimientos, pero sobre todo con muchas dudas sobre la continuidad de los negocios y sobre la utilidad de este tipo de programas. De hecho, otros programas de retorno orientados al emprendimiento de los migrantes, impulsados por organismos supranacionales como la Organización Internacional para las Migraciones o por Estados nacionales y organizaciones sin ánimo de lucro, también han mostrado sus limitaciones. Buena parte de los estudios sobre los programas de retorno productivo han destacado el reducido alcance de estos, así como las numerosas dificultades a las que se enfrentan los migrantes retornados, como ocurre en el trabajo de Ndione y Lombard (2008) sobre el Programa Desarrollo Local y Migración, impulsado por el Estado francés en Malí.

En el caso del Fondo Cucayo el estudio de Moncayo y Herrera incide en que para la mayoría de los que retornaron, el acceso al Fondo «no influyó en su decisión de regresar al Ecuador ni tampoco en su decisión de emprender un negocio propio en Ecuador. Sin embargo, sí miran la ayuda gubernamental como una oportunidad para acumular recursos y así fortalecer su proyecto de retorno, y como una manera de reafirmar su decisión de quedarse en el país" (Moncayo y Herrera, 2011: 66). Igualmente, dicho estudio destaca el bajo nivel de cobertura frente a la demanda existente, pues «apenas el $9 \%$ de las ideas recibidas son financiadas. De acuerdo con la Secretaría, este nivel de cobertura, se debe, entre otras razones, a limitaciones presupuestarias, a que los proponentes no cumplen con los requisitos de aplicación y a que las ideas presentadas no se ajustan a los criterios de evaluación» (Moncayo y Herrera, 2011: 46). Por último, las autoras ponen de relieve que "los emprendimientos analizados poseen poca ventaja frente a la competencia local puesto que se encuentran en sectores de la economía que están saturados. El hecho de que los emprendimientos constituyan un medio de subsistencia para los beneficiarios no significa necesariamente que estén generando trabajo productivo, bajo condiciones razonables, ni que estén generando suficientes beneficios" (Moncayo y Herrera, 2011: 99). Por tanto, tres serían los principales limitantes del Fondo: el retorno no se produce condicionado por el incentivo, el número de emprendimientos financiados es muy reducido y su capacidad de generar beneficios económicos y laborales es cuestionable.

Otro estudio, el realizado por Castillo (2011), destaca igualmente algunas de las limitaciones que presentan los resultados del Fondo Cucayo:

"El ingreso de la persona migrante al retornar es en promedio mensual entre 400 dólares norteamericanos a 799 dólares norteamericanos, lo que difiere del valor promedio de ingreso que mantenían cuando se encontraban en los países de destino, más de 2.000 dólares norteamericanos mensuales. El nivel académico y la experiencia en

los países de destino son una buena combinación a la hora de emprender, sin embargo esto no asegura el éxito en el negocio, ya que el $42 \%$ indican que la situación del negocio es regular al año y ocho meses de su implementación y puesta en marcha. Por último, la sensación en general de los encuestados es sentirse mejor que cuando migraron (27\%) e incluso mejor que antes de migrar $(36 \%)$, mas ésta se desvirtúa cuando se tiene un 
rotundo sí, al consultarles a los entrevistados sobre la posibilidad de volver a los países de destino en caso de que la situación del negocio y familiar se agravaran en el país de origen" (Castillo, 2011: 74).

El trabajo de Castillo muestra, pues, la debilidad y falta de garantía en la continuidad de algunos de los efectos buscados por el Fondo.

El Informe sobre Movilidad Humana Ecuador 2011, elaborado por la Coalición por las Migraciones y el Refugio (2012: 134) señala que de acuerdo con "la información recabada, las personas retornadas no han podido acceder a estos programas, ya sea porque la modalidad o los requisitos establecidos no se adecuan a su situación. En este sentido, [prosigue el Informe] un gran número de personas, sobre todo de Loja y Azuay, ha preferido recurrir a formas propias de auto-sustento, o ha formado cooperativas que les permita acceder más fácilmente a préstamos y otros beneficios".

Las observaciones contenidas en dichos estudios resultan altamente coincidentes con los resultados obtenidos durante nuestra investigación. Los migrantes que siguieron la vía del Fondo Cucayo en las provincias del Sur de Ecuador fueron mayoritariamente hombres retornados desde España, con un nivel de estudios medios y superiores, que apostaron por el sector de la industria y la manufactura o el sector de la hostelería y los restaurantes, especialmente en el medio urbano, tras haber pasado más de ocho años en el exterior, y de los que prácticamente la mitad pudo aprovechar algunas de sus experiencias laborales y conocimientos adquiridos durante la migración en actividades que no resultaban totalmente nuevas para ellos. Los negocios más exitosos fueron precisamente los de aquellos que habían trabajado antes en la misma actividad y que pudieron mejorar técnicamente en la emigración trabajando en el sector, continuando ocupados en el mismo sector al regresar. Asimismo, si bien en un número significativo de los emprendimientos hubo transferencia de conocimientos relacionados con la experiencia migratoria, dados los elevados niveles de estudios de gran parte de los retornados, quizás se podría haber promocionado en mayor medida los emprendimientos en sectores de mayor innovación.

Este último es uno de los puntos débiles del programa, pues pese a que los proyectos debieron ser seleccionados en función de su carácter innovador, gran parte de ellos no responden a esta condición. Sólo unos pocos, como la construcción de una cancha deportiva con pista sintética, una pequeña empresa de reciclaje de neumáticos y una ludoteca en Loja, una clínica dental en El Oro o un complejo de ecoturismo en Zamora, cubren necesidades que hasta el momento no se encontraban atendidas e incorporan nuevas ideas y medios técnicos. En este sentido, una mayor orientación de los emprendedores y la priorización institucional hacia determinados sectores estratégicos de actividad, podría ser más efectiva que la elección de los propios concurrentes al Fondo en función de ideas poco meditadas o recurrentes.

Aquellos que retornaron con estudios superiores se inclinaron en muchos casos por actividades relacionadas con la hostelería y la restauración, sin que probablemente pudiesen aplicar todo el potencial de sus capacidades, aunque ello no resulte ciertamente sencillo. La revisión de una buena parte de la literatura científica sobre el retorno (Ghosh, 2000; Ammassari y Black, 2001;Tiemoko, 
2004) nos muestra que la discusión en torno a la posibilidad de que los migrantes retornados se conviertan en actores de cambio y desarrollo en las sociedades de origen sigue abierta. Para los más optimistas, el capital humano adquirido con la migración puede convertirse en un estímulo para el retorno y facilitar la obtención de un mejor empleo o la gestión de un autoempleo (Durand, 2004: 112). En el extremo opuesto, se duda de la posibilidad de que dicha transferencia tenga un efecto positivo o de que esta pueda, incluso, operarse (Schramm, 2011). Por ello, uno de los retos consiste en evaluar adecuadamente las capacidades de los solicitantes, así como tener más en cuenta sus formaciones y la necesidad de complementarlas. Por ejemplo, algunos de los retornados expresaban su interés por obtener una mayor formación especializada, al tiempo que mostraban su desánimo por el tiempo perdido durante la emigración - habría que incidir más en cómo conectar la formación antes y después del retorno ${ }^{17}$.

Sobre esta cuestión, y a partir de la consulta de los expedientes de los emprendedores, durante nuestra investigación tratamos de determinar hasta qué punto había existido una posible transferencia de conocimientos (relación entre el trabajo realizado y las habilidades adquiridas en la migración y el tipo de negocio creado al retornar). El resultado, hasta cierto punto sorprendente, fue que en un $60 \%$ de los casos de los que se disponía de información se pudo corroborar la transferencia de conocimientos en el emprendimiento a partir de la experiencia migratoria (en mayor grado entre los hombres que entre las mujeres), mientras que sólo en un $11 \%$ de los casos no se habría producido esta transferencia. La transferencia se produjo de forma especial en el caso de los migrantes retornados desde Estados Unidos ${ }^{18}$ (88\% de los casos), mientras que el porcentaje de transferencia desde España fue del $62 \%$.

Por niveles de estudios, el mayor porcentaje de transferencia de conocimientos corresponde a los migrantes con estudios de bachiller $(47 \%)$ y superiores $(43 \%) y$, entre los casos en los que hubo transferencia de conocimientos, el $68 \%$ pertenece al ámbito urbano y el $32 \%$ al rural. En cuanto a las elevadas posibilidades de transferencia de conocimientos en el ámbito urbano, estas responden más bien al tipo de negocios más proclives a ese medio, como los servicios y las manufacturas.

Pese a todas las limitaciones señaladas, la valoración tanto personal por parte de los beneficiarios, como la valoración institucional por parte de los técnicos del Fondo, suele ser positiva - se habría logrado proporcionar una actividad económica a un cierto número de personas retornadas y generar cierta cantidad de empleo a partir de los emprendimientos. No obstante, habría que ir más allá y preguntarse sobre el resultado conjunto de la iniciativa y su impacto global en relación también con el coste económico que generó, así como otros tipos de costes - por ejemplo, al tratarse de un fondo concursable no todos los solicitantes, aún reuniendo los requisitos exigidos, pudieron ser receptores

17 En cambio, sí hubo casos en que los retornados ampliaron sus formaciones durante la emigración con vistas a un eventual retorno: los casos de retornados que adquirieron formación para mejorar un negocio de imprenta, un emprendimiento turístico, el trabajo de animación con niños en una ludoteca o el pilotaje de un barco de pesca.

18 Resulta ilustrativo el caso de una mujer retornada desde Estados Unidos que, pese a tener estudios primarios, trabajó allí en el procesamiento del caucho y creó en Loja un emprendimiento relacionado con el reciclado del caucho para repuestos de automóviles. 
de las ayudas y, de este modo, especialmente entre aquellos que no han visto seleccionados sus proyectos, pudo generarse un sentimiento de frustración y verse incrementada su desconfianza hacia las instituciones públicas.

Asimismo, una de las principales críticas que ha recibido el Fondo Cucayo, así como otros programas de características similares en otros países, reside en la percepción de que pueden beneficiar a quienes menos lo necesitan. Las políticas parecen orientarse no hacia aquellos que tuvieron más dificultades durante y después de la emigración, sino hacia aquellos migrantes que pueden simbolizar en mayor medida el éxito de la migración y del retorno a través del emprendimiento. Investigadores como Izaguirre, sostienen que «la acción de los Estados en el acompañamiento al retorno se hará más eficaz y útil en la medida en que se aleje de su sesgo economicista y se esfuerce por valorar otro tipo de perfiles distintos al del migrante exitoso emprendedor, perfiles para quienes la experiencia del retorno se torna efectivamente más difícil» (Izaguirre, 2011).

En realidad no hay que olvidar que la mayor parte de los retornos se producen al margen de los dispositivos oficiales, al igual que las inversiones. Aquellos migrantes que emprenden cuando regresan son una minoría entre el conjunto de los que retornan y la gran mayoría de los emprendimientos se realizan sin contar con apoyos institucionales como el Fondo Cucayo. Por ejemplo, en el centro de la ciudad de Loja, donde se concentra el grueso de la actividad comercial, son visibles los negocios regentados por migrantes retornados que han emprendido por su cuenta, junto a un pequeño número de negocios que fueron apoyados desde el Fondo Cucayo. Sin embargo, las conversaciones con los propietarios de estos negocios al margen de los apoyos institucionales nos muestran la similitud en los problemas a los que se enfrentan unos y otros (complejos trámites administrativos, dificultades de adaptación al nuevo marco, escasos beneficios, etc.). Tanto en unos casos como en otros, como retornados, hay una sensación de éxito y fracaso: no consiguieron todo lo que esperaban, pero sí alcanzaron ciertas mejoras, aunque tampoco se puede saber qué hubiese ocurrido en caso de no haber emigrado. Igualmente, en ambos casos la inversión en pequeños negocios no se sostuvo tanto en el envío de remesas - dedicadas mayormente a la inversión en la vivienda o en atender las necesidades cotidianas -, como en el recurso a fuentes externas cuando se retornó: el crédito privado para unos y el financiamiento estatal para otros, o una combinación de ambos.

\section{Conclusiones}

Con la crisis mundial iniciada en 2008 el número de retornos hacia Ecuador se incrementó, al tiempo que las salidas disminuyeron progresivamente. En paralelo a esta reinversión del flujo migratorio y, a diferencia de los años en los que se produjo la crisis financiera ecuatoriana de finales de los noventa, los indicadores de Ecuador proporcionados por el Programa de Naciones Unidas para el Desarrollo a largo de los últimos años muestran una mejora de la situación de desarrollo humano del país - entre 2007 y 2012 Ecuador habría ganado diez puestos en la lista mundial. De igual manera, las provincias del Sur comprendidas dentro de la Región 7 (Loja, Zamora y El Oro), aquellas que forman parte del ámbito de aplicación del Fondo Cucayo en nuestro caso de estudio, 
también han visto mejorar sus indicadores socio-económicos en estos últimos años, a pesar de sus condiciones de partida más desfavorables, al tiempo que la migración se redujo y, por ejemplo, en la provincia de Loja los emigrantes pasaron de representar un 6\% de la población en 2001, a representar en 2010 un $2,4 \%$, según la información censal del INEC.

No podemos saber qué hubiese ocurrido en ausencia de la crisis internacional y si los migrantes ecuatorianos habrían retornado igualmente como efecto de las mejoras en el país de origen. Podemos presuponer que la crisis aceleró la decisión del retorno para muchos de los que tenían ese horizonte en su proyecto migratorio. Una de las condiciones que precisamente pudo facilitar ese retorno fueron los incentivos que ofreció el gobierno ecuatoriano, entre ellos el propio Fondo Cucayo. La preparación del retorno de la que habla Cassarino (2004) se habría visto así afectada por la imprevisibilidad de la crisis, pero también se habría visto beneficiada y acelerada por los planes gubernamentales. Sea como sea, en la decisión de retornar influyen gran cantidad de variables, por lo que resulta difícil establecer un patrón común para el conjunto de los migrantes. Tal y como Bimal Ghosh señala, el retorno «está muy condicionado por la inicial motivación de la migración, así como por la duración de la estancia en el extranjero y, sobre todo, por las condiciones en que el retorno tiene lugar" (Ghosh, 2000: 185).

El efecto de la crisis económica internacional sobre los retornos ha sido considerable, aunque quizás no tan masivo como podría esperarse o como en ocasiones se ha publicitado. En cambio, la situación de crisis sí ha servido para argumentar el retorno de los que ya pasaron un largo número de años en el exterior, aunque no hubiesen cumplido con todos sus objetivos. En cierta medida, la crisis ayudó a legitimar el retorno en un contexto social y familiar en el que se esperaba que el migrante regresase tras haber alcanzado todas sus metas. Una de estas metas era en muchos casos la de dotarse de medios para emprender una actividad económica generadora de ingresos que permitieran una elevación del estatus. Aquellos que pudieron acceder al financiamiento del Fondo Cucayo mantenían especialmente esta expectativa.

En un plano estructural, y más allá de los beneficios personales para algunos de los retornados, es impensable que el limitado número de emprendimientos financiados pueda tener un impacto considerable sobre el desarrollo económico y social de una región tan amplia como la Región $7^{19}$. Aunque la retórica de los planes pueda tratar de destacar la función de contribuir al desarrollo local, los emprendimientos no pueden lograr por sí solos ese objetivo. En realidad, la financiación de un número limitado de emprendimientos parece obedecer más a la lógica simbólica de la visibilización del compromiso del Estado con sus ciudadanos en el exterior, que al logro material del pretendido desarrollo. A este respecto, el estudio de Moncayo y Herrera sobre el Fondo Cucayo concluye que por el momento:

19 Sesenta y un emprendimientos financiados de entre una población estimada de retornados de más de 12.000 personas en las tres provincias. 
"La mayoría de los emprendimientos analizados en esta muestra cumplen su objetivo fundamental, que consiste en generar un medio de subsistencia para los retornados. Sin embargo, para que el Fondo El Cucayo alcance su objetivo macro, es decir, para que

se convierta en una verdadera iniciativa de desarrollo que contribuya a dinamizar el tejido productivo local, no es suficiente con la creación de empleo per se, sino que esa actividad debe garantizar unas condiciones razonables y generar suficientes beneficios. Esta meta va más allá de la capacidad de los emprendedores y de la acción de la propia SENAMI y tiene relación con la articulación de la política migratoria a los demás instrumentos de política del Estado ecuatoriano. Iniciativas de promoción del retorno, como las del Cucayo, deben estar articuladas a la política pública de producción y la política pública de empleo, de lo contrario, se convierten en acciones aisladas que permiten la subsistencia del retornado pero que no necesariamente generan valor agregado ni empleo productivo" (Moncayo y Herrera, 2011 : 71).

El análisis de los datos obtenidos en nuestro estudio nos permite afirmar que la política de emprendimientos financiados por el Fondo Cucayo en la Región 7 adolece también en gran medida de esas mismas debilidades. El financiamiento de los emprendimientos permitió asegurar mejores condiciones de retorno para un número reducido de migrantes, pero cabe preguntarse si, por ejemplo, no hubiese sido más conveniente intensificar y llevar la orientación y formación sobre el emprendimiento a un mayor número de retornados, así como establecer mecanismos que faciliten y agilicen en mayor medida el acceso al crédito. La primera opción es más bien la de la obtención de resultados limitados pero visibles a corto plazo; la segunda es la de la extensión de las condiciones con un resultado incierto y a más largo término.

Podemos concluir que las dudas que plantean este tipo de programas de "retorno productivo" parecen fundamentadas. El propósito oficial de convertir a los migrantes retornados en emprendedores choca con las realidades personales y del medio local en que han de reinsertarse. Igualmente, las lógicas, dinámicas y tiempos administrativos se muestran muy alejados de las situaciones a las que se enfrentan los propios migrantes, con trámites complejos y requerimientos que desalientan las iniciativas. Los migrantes retornados aspiran a ocupar un puesto económica y socialmente por encima del que ocupaban antes de marcharse $y$, sobre todo, a ver compensada la pérdida de estatus que muchos padecieron durante su estancia en el exterior. El Estado ecuatoriano, de modo similar a otros Estados de origen de la migración, construyó un discurso en torno a los retornados como "héroes» a los que se debía recompensar. Sin embargo, pese al esfuerzo que representa la puesta en marcha de dispositivos como el Fondo Cucayo, la retórica gubernamental sigue estando muy alejada de las necesidades de la mayor parte de los retornados. 


\section{Bibliografía}

Ammassari Savina and Black Richard (2001) Harnessing the Potential of Migration and Return to Promote Development, Geneva, International Organization for Migration, $56 \mathrm{p}$.

Cassarino Jean-Pierre (2004) Theorising Return Migration: The Conceptual Approach to Return Migrants Revisited, International Journal on Multicultural Societies, $6(2)$, pp. 253-279.

Castillo Ana Lucía (2011) Impacto socioeconómico de la entrega del capital semilla del Programa Fondo Concursable "El Cucayo" a personas migrantes retornadas y a las expectativas de su proyecto de retorno, Tesis de Maestría en Alta Gerencia, Quito, IAEN.

Coalición por las Migraciones y el Refugio (2012) Informe sobre movilidad humana Ecuador 2011, 186 p., [en línea] consultado el 05/06/2014. URL: http://movilidadhumana.files.wordpress.com/2012/07/informe-movilidad-humana-ampliado.pdf

Correa Ronny (2013) Impactos de la migración internacional en las economías locales: El aporte de las remesas a las condiciones socio-económicas de las familias del Cantón Loja (Ecuador), Tesis de Grado de Doctor en Economía, México, Universidad Nacional Autónoma de México, 331 p.

Durand Jorge (2004) Ensayo teórico sobre la emigración de retorno. El principio del rendimiento decreciente, Cuadernos Geográficos, 35, pp. 103-116.

Ghosh Bimal (2000) Return migration: Reshaping policy approaches, in Bimal Ghosh Ed., Return Migration: Journey of Hope or Despair?, Geneva, International Organization for Migration, pp. 181-226.

Izaguirre Lorena (2011) De la relativa ausencia a la creciente presencia: la migración de retorno en el escenario de la Región Andina. Los casos de Perú y Ecuador, Ponencia IV Congreso de la Red Internacional Migración y Desarrollo. Crisis global y estrategias migratorias, Quito, FLACSO, 13 p.

Moncayo María Isabel y Herrera Gioconda (2011) El Plan «Bienvenid@s a Casa»: estudio sobre la experiencia del Fondo «El Cucayo», Madrid, Fundación Carolina, 121 p.

Ndione Babacar et Lombard Jerome (2008) Diagnostic des projets de réinsertion économique des migrants de retour : étude de cas au Mali (Bamako, Kayes), Revue Européenne des Migrations Internationales, 20 (1), pp. 169-195.

Nieto Carlos (2012) Migración de retorno y capital humano, Universitas, 16, pp. 53-67.

Organización Internacional para las Migraciones (2012) Perfil migratorio del Ecuador 2011, [en línea] consultado el 03/06/2014. URL: http://publications.iom. int/system/files/pdf/perfil_migratorio_del_ecuador2011.pdf

Ramírez Franklin y Ramírez Jacques (2005) La estampida migratoria. Crisis, redes transnacionales y repertorios de acción migratoria, Quito, Abya-Yala, UNESCO, CIUDAD, ALISEI, $190 \mathrm{p}$.

Schramm Christian (2011) Retorno y reinserción de migrantes ecuatorianos. $\mathrm{La}$ importancia de las redes sociales transnacionales, Revista CIDOB d'Afers Internacionals, 93-94, pp. 241-260.

SENAMI (2007) Plan Nacional de Desarrollo Humano para las Migraciones 20072010, Quito, Ministerio de Asuntos Exteriores del Ecuador, 37 p.

Tiemoko Richmond (2004) Migration, return and socio-economic change in West Africa: The role of family, Population, Space and Place, 10 (2), pp. 155-174. 


\section{Ronny Correa, Joan Lacomba y Santiago Ochoa}

\section{Crisis, retornos y emprendimientos. El caso de los migrantes ecuatorianos y el Fondo Cucayo}

Uno de los efectos más visibles de la crisis económica internacional ha sido el retorno de un importante número de migrantes a sus países de origen, entre ellos y de modo significativo, los ecuatorianos. Coincidiendo en muchos casos la pérdida de empleo con las políticas puestas en marcha por el Estado de Ecuador para facilitar el retorno de sus ciudadanos, un número considerable de inmigrantes ecuatorianos tomaron la decisión de reinstalarse en su país de origen. En este artículo analizamos estos retornos, los proyectos económicos vinculados a ellos y los efectos que los dispositivos oficiales tienen a la hora de "emprender una nueva vida» en Ecuador. De manera más específica, nuestra investigación aborda el caso del Fondo Concursable Cucayo, dirigido a facilitar el emprendimiento económico de los retornados, y sus efectos en tres provincias del Sur de Ecuador.

\section{Crises, retours et entrepreneuriats. Le cas des migrants équatoriens et le Fonds Cucayo}

Un des effets les plus visibles de la crise économique internationale a été le retour de très nombreux immigrés dans leur pays d'origine, en particulier les Équatoriens. Alors que beaucoup d'entre eux ont perdu leur emploi et que, dans le même temps, l'État équatorien a mis en œuvre des politiques pour faciliter leur retour, un nombre considérable d'Équatoriens ont pris la décision de se réinstaller dans leur pays d'origine. Dans cet article, nous nous interrogeons sur ces retours, sur les projets économiques qui en découlent et sur les effets des dispositifs officiels au moment de redémarrer une nouvelle vie en Équateur. Notre recherche porte plus précisément sur le Fonds Compétitif Cucayo, programme visant à faciliter l'entrepreneuriat économique des rapatriés, et sur I'ampleur de ses effets dans trois provinces du sud de l'Équateur.

\section{Crisis, Returns and Entrepreneurship. \\ The Case of Ecuadorian Migrants and the Cucayo Fund}

One of the most visible effects of the international economic crisis has been the return of a significant number of immigrants to their home countries, including, in particular Ecuadorians. Coinciding, in many cases, with the loss of their jobs and the policies implemented by the Ecuadorian State to facilitate the return of its citizens, a considerable amount of Ecuadorian immigrants made the decision to resettle in their home country. In this article we contemplate the socio-economic projects linked to this return and also the effect of official arrangements when restarting a new life in Ecuador. In particular, our research addresses the case of the Cucayo Competitive Fund, aimed at facilitating the economic entrepreneurship of returnees and its effects and scope in the three southern provinces of Ecuador. 